\title{
Drop in lung function during asthma and COPD exacerbations - can it be assessed without spirometry?
}

\author{
Hasse Melbye' \\ Salwan Al-ani' \\ Mark Spigt ${ }^{1,2}$
}

'General Practice Research Unit, Department of Community Medicine, UIT The Arctic University of Norway, Troms $\varnothing$, Norway; ${ }^{2}$ Department of Family Medicine, CAPHRI, Maastricht University, Maastricht, the Netherlands
Correspondence: Hasse Melbye General Practice Research Unit, Department of Community Medicine, MH Building, UIT The Arctic University of Norway, 9037 Tromsø, Norway Tel +47 77 952I 3200 Email hasse.melbye@uit.no
This article was published in the following Dove Press journal: International Journal of COPD

8 December 2016

Number of times this article has been viewed

Background: When assessing patients with exacerbation of asthma or COPD, it may be useful to know the drop in forced expiratory volume in 1 second $\left(\mathrm{FEV}_{1}\right)$ compared with stable state, in particular when considering treatment with oral corticosteroids. The objective of the study was to identify indicators of drop in $\mathrm{FEV}_{1}$ during exacerbations.

Methods: In this prospective multicenter study from primary care, patients diagnosed with asthma or COPD were examined at stable state and during exacerbations the following year. Symptoms, chest findings, and pulse oximetry were recorded, and spirometry was performed. A fixed drop in $\mathrm{FEV}_{1}(10 \%$ and $\geq 200 \mathrm{~mL})$ and percentage change in $\mathrm{FEV}_{1}$ were outcomes when possible indicators were evaluated.

Results: Three hundred and eighty patients attended baseline examination, and 88 with a subsequent exacerbation were included in the analysis. Thirty (34\%) had a significant drop in $\mathrm{FEV}_{1}(10 \%$ and $200 \mathrm{~mL})$. Increased wheezing was the only symptom associated with this drop with a likelihood ratio of 6.4 (95\% confidence interval, 1.9-21.7). Crackles and any new auscultation finding were also associated with a significant drop in $\mathrm{FEV}_{1}$, as was a $\geq 2 \%$ drop in oxygen saturation $\left(\mathrm{SpO}_{2}\right)$ to $\leq 92 \%$ in the subgroup diagnosed with COPD. Very bothersome wheezing and severe decrease in $\mathrm{SpO}_{2}$ were also very strong predictors of change in $\mathrm{FEV}_{1}$ in linear regression adjusted for age, gender, and baseline $\mathrm{FEV}_{1} \%$ predicted.

Conclusion: Increased wheezing, as experienced by the patient, and a decreased $\mathrm{SpO}_{2}$ value strongly indicated a drop in lung function during asthma and COPD exacerbations and should probably be taken into account when treatment with oral corticosteroids is considered.

Keywords: bronchial obstruction, systemic corticosteroids, diagnostic tests, primary care

\section{Background}

Patients with COPD or asthma frequently experience exacerbations of their illness. Studies from Norway and the UK have shown that each year $\sim 50 \%$ of COPD patients experience an exacerbation that leads to a visit to a general practitioner (GP), in-hospital treatment, or self-administered treatment with antibiotics or systemic corticosteroids. ${ }^{1,2}$ In a study from the United States, $\sim 25 \%$ of asthma patients reported to use a short course with oral corticosteroids during a period of 3 months. ${ }^{3}$ Treatment with systemic corticosteroids is recommended in both severe COPD exacerbations ${ }^{4,5}$ and asthma attacks. ${ }^{6,7}$ Such medication counteracts the inflammatory response in the bronchial tree, and by doing so, alleviates the accompanying bronchial obstruction. In asthma attacks, there is firm evidence for a favorable effect of systemic corticosteroids, ${ }^{6}$ for COPD exacerbations the evidence refers mainly to clinical trials in hospitalized patients. ${ }^{4}$ In COPD guidelines, the criteria for starting 
such treatment are not clear cut, but it is often recommended when symptoms are not relieved after stepping up treatment with inhaled bronchodilators. ${ }^{8}$ Benefit from systemic corticosteroid treatment has to be weighed against adverse effects, such as increased fragility of the bones and increased blood levels of glucose. ${ }^{4}$

Improvement in lung function has been a main outcome measure in studies on the effects of systemic corticosteroids. ${ }^{9,10}$ This implies that the acute deterioration of lung function associated with the exacerbation is a main target for the systemic corticosteroids. It would, therefore, probably be useful, when deciding on prescribing systemic corticosteroids, to know whether the patient actually suffers from increased bronchial obstruction and if so, to which degree? However, doing spirometry in the acute phase of a COPD exacerbation is not recommended in the Global Initiative for Chronic Obstructive Lung Disease (GOLD) guidelines, ${ }^{5}$ and it might not be convenient in all cases with asthma attacks. Other sources of information that could reflect increased bronchial obstruction could be the symptoms of the patient, as well as chest findings and assessment of oxygen saturation $\left(\mathrm{SpO}_{2}\right)$ by pulse oximetry. The aim of this study was to describe how these clinical findings are associated with a decrease in lung function during exacerbations. We also wanted to find out whether the strength of these associations would be affected when they could be described in terms of change from stable state.

\section{Methods}

\section{Study sample}

This observational prospective study was carried out in seven general practice offices in the north and south of Norway. Patients aged 40 years or older registered in the electronic medical record with a diagnosis of asthma or COPD (or both) in the previous 5 years were identified, and a random sample of 1,111 patients was invited to participate. Of the 380 patients who met for baseline registration between April 2009 and March 2010, 376 were considered to be in a stable phase of their disease and were included in the study. Out of those, 210 were diagnosed with asthma by their GPs, 74 with COPD, and 92 with both asthma and COPD. ${ }^{11}$ They were all asked to visit their GP within 2-3 days if they experienced exacerbations of their lung disease the following 12 months.

All participants gave written consent, and the study was approved by the Regional Committee for Medical and Health Research Ethics in North Norway.

\section{Examinations at baseline}

Respiratory symptoms the previous week and relevant quality of life items were examined using the Norwegian translation of the Clinical COPD Questionnaire (CCQ). ${ }^{12}$ In the CCQ, the symptoms "short of breath at rest", "short of breath doing physical activities", coughing, and production of phlegm were classified into scores from 0 (never) to 6 (almost all the time), and a mean score of respiratory symptoms was calculated. The CCQ also contains questions on depression and concern about the disease getting worse with the same score system and four questions on activity limitation due to the illness, also with a score system from 0 (not limited at all) to 6 (totally limited). A total CCQ score as the mean of all 10 items was also calculated. Smoking habit and hospitalizations due to the lung disease the previous year were reported on a separate questionnaire. On a pop-up questionnaire in the electronic medical record the examining GP recorded comorbidities and treatment given, including antibiotics and systemic corticosteroids for exacerbations the previous year. Exacerbation of asthma or COPD the year before baseline was defined as exacerbations that were treated with antibiotics and/or systemic corticosteroids or ended with hospitalization, a definition previously used for COPD exacerbations. ${ }^{1}$ The GPs also reported the presence of wheezes, crackles, diminished breath sounds, and prolonged expiration after auscultation of the lungs. The examinations at baseline were shared between 20 GPs.

C-reactive protein (CRP) was analyzed using near patient tests: Afinion AS100 Analyzer, Orion Quickread CRP, or ABX Micros CRP, which all could display values down to $8 \mathrm{mg} / \mathrm{L}$. $\mathrm{SpO}_{2}$ was measured by a digital handheld pulse oximeter, Onyx II model 0550 (Nonin Medical, Inc., Plymouth, MN, USA). The highest value of the three measurements was recorded.

Spirometry was carried out after the pulse oximetry, following the European Respiratory Society/American Thoracic Society guidelines. ${ }^{13}$ Spirare SPS310 spirometers (Diagnostica AS, Oslo, Norway) were used. The patients were seated, and nose clip was not used. Post-bronchodilator spirometry was carried out 20 minutes after inhalation of $0.4 \mathrm{mg}$ salbutamol. The post-bronchodilator forced expiratory volume in 1 second $\left(\mathrm{FEV}_{1}\right)$ and forced vital capacity (FVC) were used in the analyses. Norwegian reference values for spirometry were applied. ${ }^{14}$

\section{Examinations at exacerbations}

The participants filled in the CCQ, this time concerning the previous 24 hours. Respiratory symptoms the previous 
24 hours were also reported by the GPs based on history taking on a pop-up questionnaire and shortness of breath, coughing, phlegm production, and wheezing were classified into three grades: 1) not present or as normal, 2) more bothersome than normal, and 3) very bothersome. The GPs also recorded whether the sputum was yellowish or green. Chest findings, the CRP value, and pulse oximetry were recorded as done at baseline. Lung function testing was also carried out with the same procedure, but post-bronchodilator spirometry was not carried out.

\section{Statistical analysis}

A significant drop in $\mathrm{FEV}_{1}$ was defined as a drop of $\geq 10 \%$ from baseline ${ }^{15}$ and of at least $200 \mathrm{~mL}$. How such a drop in $\mathrm{FEV}_{1}$ was associated with baseline characteristics and symptoms, signs and test results at exacerbation was analyzed by chi-square test, Fischer's exact test (dichotomous variables), and Mann-Whitney test (the CCQ variables). The threshold used for raised CRP value was $\geq 20 \mathrm{mg} / \mathrm{L}$. Two thresholds were used for $\mathrm{SpO}_{2}, \leq 92 \%$ and $\leq 95 \%$. Changes from baseline were found by subtracting baseline values from the values at exacerbation. Significant increase in CRP was defined as an increase of at least $10 \mathrm{mg} / \mathrm{L}$ to a value of $\geq 20 \mathrm{mg} / \mathrm{L}$. Significant decreases in $\mathrm{SpO}_{2}$ were defined as a reduction of at least $2 \%$ to $\leq 95 \%$ and $\leq 92 \%$, respectively. Likelihood ratios were calculated for findings significantly associated with the fixed drop in $\mathrm{FEV}_{1}$ using online software (M.K. Anders Consulting). Associations with percentage change in $\mathrm{FEV}_{1}$ from baseline were analyzed by linear regression making it possible to have the degree of change as outcome. IBM SPSS Statistics software version 22 was used.

\section{Results}

During the 1-year follow-up period, 109 patients visited their GP due to one or more exacerbations. For patients who visited the GP with several exacerbations, the first exacerbation was, as a rule, included in the analysis. However, 21 patients were excluded due to incomplete data from the exacerbations, in most cases because spirometry was not done. Seventeen GPs took part in the examinations of the 88 included patients at baseline, whereas 34 GPs shared the examinations during the exacerbations, and 41 patients (47\%) were examined by the same GP both times. The mean age of the patients at baseline was 63 years, and 66\% were female. A COPD diagnosis (or both asthma and COPD) had been given to 48 (55\%) patients at baseline, and patients with a COPD diagnosis had significantly more frequent history of exacerbation the previous year. They were also different from the patients in the asthma group in other ways (Table 1).

The distribution of $\mathrm{FEV}_{1}$ at baseline and at exacerbation is shown in Figure 1, with predicted mean values of $76.1 \%$ and $70.8 \%$, respectively. Among the asthma patients, the corresponding $\mathrm{FEV}_{1} \%$ predicted values were 87.5 and 83.0 and

Table I Baseline characteristics of 88 adult patients with asthma or COPD

\begin{tabular}{|c|c|c|c|c|}
\hline Patient characteristics & $\begin{array}{l}\text { All, } n=88 \\
n(\%)\end{array}$ & $\begin{array}{l}\text { Diagnosed with asthma } \\
\text { only, } n=40, n \text { (\%) }\end{array}$ & $\begin{array}{l}\text { Diagnosed with COPD or both } \\
\text { asthma and COPD, } n=48, n(\%)\end{array}$ & P-value \\
\hline Age $\geq 65$ years & $43(49)$ & $16(40)$ & $27(56)$ & 0.1 \\
\hline Male gender & $34(39)$ & $16(40)$ & $18(38)$ & 0.8 \\
\hline Current smoker & $27(3 \mathrm{I})$ & $9(23)$ & $18(38)$ & 0.1 \\
\hline \multicolumn{5}{|l|}{ Comorbidity } \\
\hline Coronary heart disease & $15(17)$ & $4(10)$ & II (23) & $0 . I^{\mathrm{a}}$ \\
\hline Diabetes & $4(5)$ & $0(0)$ & $4(8)$ & $0.1^{a}$ \\
\hline Exacerbation the previous year & $48(55)$ & $17(37)$ & $31(63)$ & 0.01 \\
\hline Treated daily with bronchodilator or ICS & $7 I(8 I)$ & $30(75)$ & $41(85)$ & 0.2 \\
\hline Treated daily with LABA/ICS ${ }^{b}$ & $47(54)$ & $21(53)$ & $26(54)$ & 0.9 \\
\hline Wheezes & $22(25)$ & $4(10)$ & $18(38)$ & $0.003^{\mathrm{a}}$ \\
\hline Crackles & II (13) & $2(5)$ & $9(19)$ & $0.06^{\mathrm{a}}$ \\
\hline Diminished breath sounds & $20(23)$ & $3(8)$ & $17(35)$ & $0.002^{\mathrm{a}}$ \\
\hline Prolonged expiration & $20(23)$ & $2(5)$ & $18(38)$ & $<0.00 I^{\mathrm{a}}$ \\
\hline $\mathrm{FEV}_{\mathrm{I}} / \mathrm{FVC}$ ratio $<0.7$ & $38(43)$ & $7(18)$ & $31(66)$ & $<0.001$ \\
\hline$C R P \geq 8 \mathrm{mg} / \mathrm{L}$ & $12(14)$ & $7(18)$ & $5(10)$ & 0.3 \\
\hline $\mathrm{SpO}_{2}{ }^{\mathrm{c}} \leq 95 \%$ & $15(17)$ & $4(10)$ & II (23) & $0.1^{\mathrm{a}}$ \\
\hline $\mathrm{SpO}_{2}{ }^{\mathrm{c}} \leq 92 \%$ & I (I) & $0(0)$ & I (2) & $I^{a}$ \\
\hline
\end{tabular}

Notes: aFisher's exact test used. ' $\mathrm{C}$ Combined inhaled medication with long-acting beta2 agonist and corticosteroids. 'One missing.

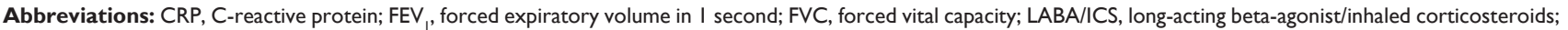
$\mathrm{SpO}_{2}$, oxygen saturation. 


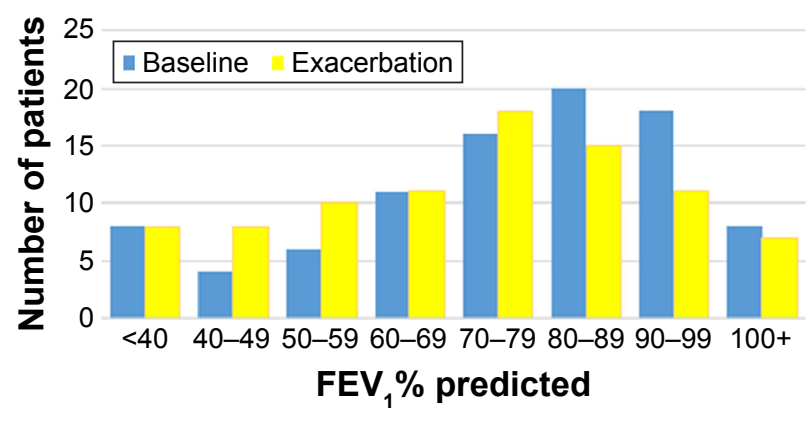

Figure I Distribution of FEV \% predicted at baseline and during excerbation in 88 patients diagnosed with asthma or COPD.

Abbreviation: $\mathrm{FEV}_{1}$, forced expiratory volume in I second.

among the COPD patients, 61.2 and 54.7. The distribution of change from baseline is shown in Figure 2. A significant drop in $\mathrm{FEV}_{1}$ at exacerbation $(10 \%$ and at least $200 \mathrm{~mL})$ was found in 30 patients (34\%). The patients with this drop in lung function had more frequent COPD diagnosis at baseline than those without $(P=0.04$, Table 2$)$. During spirometry at baseline 75 patients ( $85 \%$ ) expired for more than 6 seconds, at exacerbation the corresponding number was $67(76 \%)$.

Increased wheezing was the only symptom associated with a significant drop in lung function. Ten of the 13 patients who reported very bothersome wheezing had a significant drop in $\operatorname{FEV}_{1}(P=0.001$, Table 2$)$. In the asthma group, only two patients had this symptom, but a significant drop in $\mathrm{FEV}_{1}$ was found in both.

An abnormal finding by chest auscultation was found in 68 patients (77\%), and a new sign (not recorded at baseline) was found in 48 patients (55\%). Any abnormal chest sign, whether new or not, was recorded more frequently in patients with a significant drop in $\mathrm{FEV}_{1}$ (Table 2) compared with other patients. The sign "crackles" was associated with a drop in

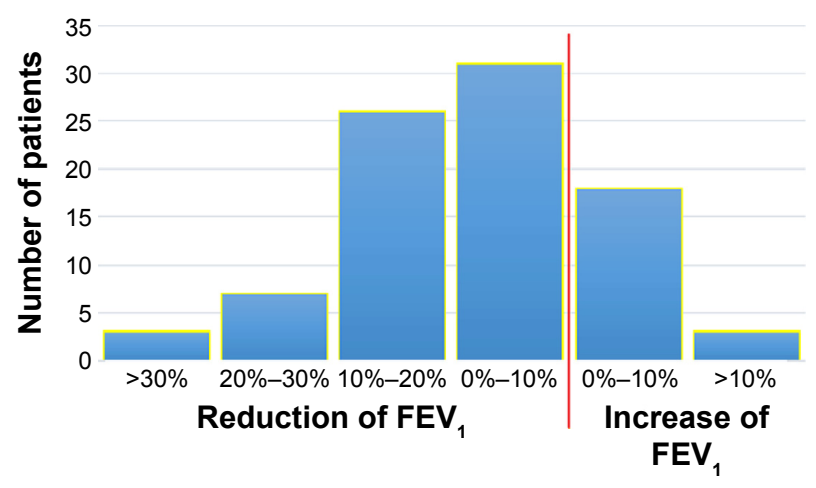

Figure 2 Distribution of change in $\mathrm{FEV} \%$ predicted between baseline and exacerbation in 88 patients diagnosed with asthma or COPD. Abbreviation: $\mathrm{FEV}_{\text {, }}$, forced expiratory volume in I second.
$\mathrm{FEV}_{1}$, whereas "wheezes" was not. In 26 patients $(30 \%)$, one or more of the four chest signs were recorded both at baseline and exacerbation, and with similar frequency whether the same GP performed the auscultation at both occasions, $24 \%$ and $34 \%$, respectively $(P=0.3) . \mathrm{SpO}_{2}$ values $\leq 92 \%$ were found in 11 patients, and in 10 of these, the saturation had dropped $2 \%$ or more between baseline and exacerbation. This drop in $\mathrm{SpO}_{2}$ was associated with a significant drop in $\mathrm{FEV}_{1}(P=0.02)$.

There was a median increase in CCQ score of 1.25 for respiratory symptoms between baseline and exacerbation, but no difference was found between the patients with a significant drop in $\mathrm{FEV}_{1}$ and the other patients (Table 3).

The diagnostic value of findings, significantly indicating a drop in $\mathrm{FEV}_{1}$, is shown in Table 4. The asthma and COPD subgroups did not differ when it came to likelihood ratios of very bothersome wheezing experienced by the patients and crackles on auscultation. A diagnostic value of $\mathrm{SpO}_{2}$ dropping to below $93 \%$ was only found in the COPD group.

When the percentage drop in $\mathrm{FEV}_{1}$ was used as outcome in univariable linear regression, the $\mathrm{FEV}_{1} / \mathrm{FVC}$ ratio was the strongest predictor among the baseline characteristics (Table 5). Treatment with long-acting beta-agonist/inhaled corticosteroids seemed to slightly counteract the drop in $\mathrm{FEV}_{1}$, but this association was not statistically significant. Very bothersome wheezing during exacerbation, as experienced by the patient, was the strongest indicator of change in $\mathrm{FEV}_{1}$ among the symptoms, and prolonged expiration and any abnormal auscultation finding were now stronger indicators than crackles. A decrease in $\mathrm{SpO}_{2}$ of at least $2 \%$ to a value of $\leq 92 \%$ was still strongly associated with a drop in $\mathrm{FEV}_{1}$.

\section{Discussion \\ Main findings}

We have attempted to find alternatives to spirometry in assessing drop in lung function during asthma and COPD exacerbations. One strong indicator of a significant drop in lung function was increased wheezing as experienced by the patient. As far as we know, this finding has not been reported previously to be a sign of a drop in lung function. Patient experienced wheezing was a stronger predictor of drop in lung function than were wheezes on auscultation.

Decreased $\mathrm{SpO}_{2}$ measured as $\mathrm{SpO}_{2} \leq 92 \%$ was also strongly associated with a drop in $\mathrm{FEV}_{1}$. Only one COPD patient had $\mathrm{SpO}_{2} \leq 92 \%$ at baseline, telling us that this is a relevant finding for primary care. A drop in $\mathrm{FEV}_{1}$ was most 
Table 2 Patient characteristics, symptoms, and findings and their association with a significant drop in FEV, at exacerbation (I0\% and at least $200 \mathrm{~mL}$ from baseline) in 88 patients diagnosed with asthma or COPD

\begin{tabular}{|c|c|c|c|}
\hline \multirow[t]{2}{*}{ Patient characteristics } & \multicolumn{3}{|c|}{ Significant drop in FEV $(10 \%$ and $\geq 200 \mathrm{~mL})$} \\
\hline & $\begin{array}{l}\text { No }(n=58) \\
n(\%)^{\mathrm{a}}\end{array}$ & $\begin{array}{l}\text { Yes }(n=30) \\
n(\%)^{b}\end{array}$ & $P$-value \\
\hline \multicolumn{4}{|l|}{ Baseline characteristics } \\
\hline Age $\geq 65$ years & $22(42)$ & $21(58)$ & 0.1 \\
\hline Male gender & $21(36)$ & $13(43)$ & 0.97 \\
\hline $\begin{array}{l}\text { Diagnosed with COPD or both } \\
\text { asthma and COPD }\end{array}$ & $27(47)$ & $2 I(7 I)$ & 0.04 \\
\hline $\begin{array}{l}\text { Exacerbation the year before } \\
\text { baseline }\end{array}$ & $29(50)$ & $16(53)$ & 0.8 \\
\hline $\mathrm{FEV}_{\mathrm{I}} / \mathrm{FVC}$ ratio $<0.7$ & $21(26)$ & $17(57)$ & 0.07 \\
\hline $\begin{array}{l}\text { Treated daily with bronchodilator } \\
\text { or ICS }\end{array}$ & $48(83)$ & $23(77)$ & 0.5 \\
\hline Treated daily with LABA/ICS & $32(55)$ & $15(50)$ & 0.6 \\
\hline \multicolumn{4}{|l|}{ Respiratory symptoms at exacerbation } \\
\hline \multicolumn{4}{|l|}{ Shortness of breath } \\
\hline No or as normal & $3(5)$ & I (3) & $0.09^{c}$ \\
\hline More bothersome than normal & $39(67)$ & $15(50)$ & \\
\hline Very bothersome & $16(27)$ & $14(46)$ & \\
\hline \multicolumn{4}{|l|}{ Coughing } \\
\hline No or as normal & $6(10)$ & $3(10)$ & $0.6^{c}$ \\
\hline More bothersome than normal & $35(60)$ & $16(53)$ & \\
\hline Very bothersome & $17(29)$ & $11(36)$ & \\
\hline \multicolumn{4}{|l|}{ Phlegm } \\
\hline No or as normal & $13(22)$ & $9(30)$ & $0.7^{c}$ \\
\hline More bothersome than normal & $37(64)$ & $13(43)$ & \\
\hline Very bothersome & $8(14)$ & $8(27)$ & \\
\hline \multicolumn{4}{|l|}{ Wheezing } \\
\hline No or as normal & $26(45)$ & $7(23)$ & $0.00 \mathrm{I}^{\mathrm{c}}$ \\
\hline More bothersome than normal & $29(50)$ & $13(43)$ & \\
\hline Very bothersome & $3(5)$ & $10(33)$ & \\
\hline \multicolumn{4}{|l|}{ Purulence } \\
\hline No or as normal & $28(48)$ & $19(63)$ & 0.2 \\
\hline Increased & $30(52)$ & $11(37)$ & \\
\hline \multicolumn{4}{|l|}{ Chest signs at exacerbation } \\
\hline Wheezes & $27(47)$ & $15(50)$ & 0.8 \\
\hline New, compared to baseline & $16(28)$ & $9(30)$ & 0.8 \\
\hline Crackles & $10(17)$ & $15(50)$ & 0.001 \\
\hline New, compared to baseline & $8(14)$ & $13(43)$ & 0.002 \\
\hline Prolonged expiration & $25(43)$ & $17(57)$ & 0.2 \\
\hline New, compared to baseline & $19(33)$ & $10(33)$ & 1.0 \\
\hline Diminished breath sounds & $10(17)$ & $8(27)$ & 0.3 \\
\hline New, compared to baseline & $5(9)$ & $5(17)$ & 0.5 \\
\hline Any chest finding & $34(59)$ & $24(80)$ & 0.05 \\
\hline New, compared to baseline & $26(45)$ & $22(73)$ & 0.01 \\
\hline \multicolumn{4}{|l|}{ Biomarkers at exacerbation } \\
\hline CRP $>20$ mg/L (3 missing) & $7(13)$ & $6(21)$ & 0.3 \\
\hline CRP $10 \mathrm{mg} / \mathrm{L}$ increase to $\geq 20 \mathrm{~m} / \mathrm{L}$ & $7(13)$ & $5(17)$ & 0.6 \\
\hline $\mathrm{SpO}_{2} \leq 95 \%$ (9 missing $)$ & $14(28)$ & $10(36)$ & 0.4 \\
\hline $\mathrm{SpO}_{2} 2 \%$ decrease to $\leq 95 \%$ & $7(14)$ & $9(32)$ & 0.05 \\
\hline $\mathrm{SpO}_{2} \leq 92 \%$ & $4(8)$ & $7(25)$ & $0.04^{d}$ \\
\hline $\mathrm{SpO}_{2} 2 \%$ decrease to $\leq 92 \%$ & $3(6)$ & $7(25)$ & $0.02^{\mathrm{b}}$ \\
\hline
\end{tabular}

Notes: a'Subtracting the percentage from 100 gives the specificity. ${ }^{\mathrm{b}} \mathrm{Can}$ also be read as sensitivity. 'Chi-square trend. ${ }^{\mathrm{C}}$ Fisher's exact test.

Abbreviations: CRP, C-reactive protein; FEV , forced expiratory volume in I second; FVC, forced vital capacity; LABA/ICS, long-acting beta-agonist/inhaled corticosteroids; $\mathrm{SpO}_{2}$, oxygen saturation. 
Table 3 Median CCQ scores at exacerbation and change in median CCQ score compared with baseline, and significant drop in $\mathrm{FEV}$, from baseline $(10 \%$ and $\geq 200 \mathrm{~mL})$ in 78 patients $^{\mathrm{a}}$ diagnosed with asthma or COPD

\begin{tabular}{|c|c|c|c|}
\hline \multirow[t]{2}{*}{ Symptoms and CCQ scores } & \multicolumn{2}{|c|}{$\begin{array}{l}\text { A drop in FEV, from } \\
\text { baseline of } 10 \% \text { and } \\
\geq 200 \mathrm{~mL}\end{array}$} & \multirow[t]{2}{*}{$P$-value ${ }^{b}$} \\
\hline & No & Yes & \\
\hline Shortness of breath at rest $(n=78)$ & 2 & 2 & 0.2 \\
\hline Change from baseline $(n=77)$ & I & 1 & 0.4 \\
\hline Shortness of breath on effort $(n=78)$ & 4 & 4 & 0.9 \\
\hline Change from baseline $(n=77)$ & 2 & 1 & 0.09 \\
\hline Cough (n=78) & 4 & 4 & 0.9 \\
\hline Change from baseline $(n=78)$ & 1 & I & 0.2 \\
\hline Phlegm (n=78) & 3 & 3 & 0.6 \\
\hline Change from baseline & 0 & 1 & 0.2 \\
\hline CCQ respiratory score $(n=75)$ & 3.5 & 3.25 & 0.5 \\
\hline Change from baseline $(n=73)$ & 1.25 & 1.0 & 0.6 \\
\hline CCQ total score $(n=74)$ & 2.6 & 2.6 & 0.8 \\
\hline Change from baseline & 1.05 & 0.7 & 0.9 \\
\hline
\end{tabular}

Notes: an 10 of the 88 patients in the study sample, CCQ was not filled in at exacerbation. 'Mann-Whitney test.

Abbreviations: CCQ, Clinical COPD Questionnaire; FEV , forced expiratory volume in I second.

frequently found in the patients with a COPD diagnosis, and the $\mathrm{FEV}_{1} / \mathrm{FVC}$ ratio at baseline was strongly associated with a change in lung function in the linear regression, indicating that the severity of the COPD should be taken into account.

\section{Strengths and limitations}

As part of a prospective study with baseline examinations, we were able to collect post-bronchodilator spirometry at

Table 4 Likelihood ratio of selected findings for a significant drop in $\mathrm{FEV}$, at exacerbation ( $10 \%$ and at least $200 \mathrm{~mL}$ from baseline) in 88 patients diagnosed with asthma or COPD

\begin{tabular}{|c|c|c|c|}
\hline \multirow[t]{2}{*}{ Findings } & \multicolumn{3}{|c|}{ Likelihood ratio ( $95 \%$ confidence interval) } \\
\hline & $\begin{array}{l}\text { Asthma group, } \\
n=40\end{array}$ & $\begin{array}{l}\text { COPD } \\
\text { group, } n=48\end{array}$ & All, $n=88$ \\
\hline $\begin{array}{l}\text { Wheezing, very } \\
\text { bothersome, at } \\
\text { exacerbation }\end{array}$ & $\infty$ & $3.3(1.0-11.4)$ & $6.4(1.9-21.7)$ \\
\hline $\begin{array}{l}\text { Crackles, at } \\
\text { exacerbation }\end{array}$ & $3.4(1.1-11.1)$ & $2.4(1.0-5.3)$ & $2.9(1.5-5.7)$ \\
\hline $\begin{array}{l}\text { Any new chest finding } \\
\text { at exacerbation } \\
\text { compared to baseline }\end{array}$ & $1.7(0.9-3.3)$ & I.5 (I.0-2.3) & $1.6(1.1-2.3)$ \\
\hline $\begin{array}{l}\mathrm{SpO}_{2}{ }^{\text {a }} 2 \% \text { decrease } \\
\text { from baseline } \\
\text { to } \leq 92 \%\end{array}$ & 0 & $5.1(1.2-22.0)$ & $4.3(1.2-15.2)$ \\
\hline
\end{tabular}

Note: ${ }^{\text {aNine missing. }}$

Abbreviations: $\mathrm{FEV}_{1}$, forced expiratory volume in I second; $\mathrm{SpO}_{2}$, oxygen saturation.
Table 5 Associations analyzed by linear regression ${ }^{\text {a }}$ between baseline characteristics and symptoms and findings at exacerbation and the percentage drop in FEV , from baseline in 88 patients diagnosed with asthma or COPD

\begin{tabular}{lll}
\hline $\begin{array}{l}\text { Patient characteristics, } \\
\text { symptoms and findings }\end{array}$ & Beta & P-value \\
\hline Baseline characteristics & & \\
Diagnosed with COPD & -5.6 & 0.05 \\
History of frequent exacerbations & -2.1 & 0.4 \\
FEV/FVC ratio at baseline & 0.39 & 0.002 \\
$\mathrm{FEV}_{1} / \mathrm{FVC}$ ratio $<0.7$ at baseline & -4.8 & 0.1 \\
Daily treatment with LABA/ICS & 3.5 & 0.1 \\
Symptoms at exacerbation & & \\
Short of breath, very bothersome & -5.2 & 0.04 \\
Coughing, very bothersome & -3.5 & 0.2 \\
Phlegm, very bothersome & -6.2 & 0.06 \\
Wheezing, very bothersome & -15.5 & $<0.001$ \\
Purulence, increased & 1.3 & 0.6 \\
Findings at exacerbation & & \\
Wheezes & -1.7 & 0.5 \\
Crackles & -4.7 & 0.08 \\
Prolonged expiration & -5.4 & 0.02 \\
Diminished breath sounds & -4.7 & 0.8 \\
Any chest finding & -5.7 & 0.02 \\
$\mathrm{CRP}^{\mathrm{b}}>20$ mg/L (3 missing) & -8.4 & 0.02 \\
$\mathrm{SpO}_{2}{ }^{\mathrm{C}} \leq 95 \%$ (9 missing) & -5.2 & 0.08 \\
$\mathrm{SPO}_{2} \leq 92 \%$ (9 missing) & -11.9 & 0.001 \\
\hline
\end{tabular}

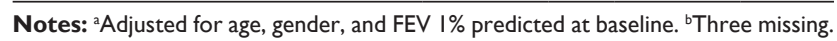
'Nine missing.

Abbreviations: CRP, C-reactive protein; $\mathrm{FEV}_{1}$, forced expiratory volume in I second; FVC, forced vital capacity; LABA/ICS, long-acting beta-agonist/inhaled corticosteroids; $\mathrm{SpO}_{2}$, oxygen saturation.

stable state in all patients. The spirometry was well performed, and although fewer patients expired for more than 6 seconds during exacerbation than at baseline, there are reasons to believe that valid $\mathrm{FEV}_{1}$ values were obtained. The cutoff level of $10 \%$ for drop in $\mathrm{FEV}_{1}$ may be regarded as arbitrary, and the results are strengthened by using the percentage drop in $\mathrm{FEV}_{1}$ as continuous outcome variable in linear regression.

Findings at exacerbation could also be shown as new findings compared to stable state. However, we did not find any great benefit of taking the baseline findings into account.

One may question whether including both COPD and asthma patients was a good idea. One good reason for doing this is the difficulties in differentiating between asthma and COPD in many patients with obstructive lung disease. ${ }^{11,16} \mathrm{~A}$ second justification is the similar challenges in the two diseases when it comes to treating exacerbations with oral corticosteroids.

This is rather a small clinical study, and the results should be interpreted with caution. Not all patients who were assessed during exacerbation were included, due to incomplete data collection in the practices. Whereas the collection of baseline data was well organized, the participating practices were not always as prepared when it came to the exacerbations. 
This has probably not resulted in any systematic selection bias influencing the association between findings and drop in lung function.

\section{Comparisons with existing literature}

We have not found studies evaluating wheezing, as experienced by patients, as a sign of drop in lung function, only as an independent predictor of COPD in general. ${ }^{17}$ Wheezing is not one of the items in score sheets for health status in COPD patients, such as the CCQ ${ }^{12}$ and the COPD assessment test $(\mathrm{CAT})^{18}$ and neither in the exacerbations of chronic pulmonary disease tool (EXACT). ${ }^{19}$

Decreased $\mathrm{SpO}_{2}$ during COPD exacerbations has been shown in previous studies, ${ }^{20,21}$ but decreased $\mathrm{SpO}_{2}$ has not previously been linked to the magnitude of drop in $\mathrm{FEV}_{1}$. A strong link between reduced $\mathrm{FEV}_{1}$ and reduced pulse oximetry values has been shown in several studies, also among asthma and COPD patients in general practice. ${ }^{22}$ Introduction of pulse oximeters in primary care was recommended in 2010, ${ }^{23}$ and our results support this development.

In a previous publication from this project, we showed that decreased $\mathrm{SpO}_{2}$ predicted treatment with oral corticosteroids. ${ }^{24}$ There was, however, no association between patient experienced wheezing and the prescribing of oral corticosteroids (among the 13 patients with very bothersome wheezing, 6 [46.2\%] were treated with oral corticosteroids, compared to $40 \%$ in the remaining patients).

One may question why not just spirometry can be used in the assessment of lung function during asthma and COPD exacerbations. It was successfully applied in this study and has also been performed in other studies without reports of adverse experiences. ${ }^{9,10}$ The recommendation in the GOLD guidelines, not to use spirometry during exacerbations, ${ }^{5}$ is probably based on experiences from hospital and with severely ill outpatients. In primary care, the majority of COPD patients have a mild or moderate disease, as was also the case in this study. When a spirometry result from stable state is available and performed within the previous year, a new spirometry can usually give a valid measure of drop in lung function. However, coughing may force the patient to terminate the expiratory maneuver too early, and this may explain why the expiration lasted less than 6 seconds more frequently during exacerbation than at baseline in this study. Clinical assessment without spirometry is often needed.

To find wheezes by auscultation of the chest might be more useful in clinical practice than shown in this study. Wheezes were recorded as present or absent, but their intensity in terms of number and duration was not documented. Consequently, when wheezes were recorded as present in both stable state and during exacerbation, we had no information about the change in the intensity. This can also explain why comparison with stable state was of little help. The difficulties in interpreting auscultation findings also relate to crackles and prolonged expiration, which were stronger indicators of a drop in $\mathrm{FEV}_{1}$ than wheezes in this study.

To ask primary care patients with asthma or COPD exacerbations about wheezing seems to be a simple and a rational approach when assessing change in lung function. Measuring $\mathrm{SpO}_{2}$ with pulse oximetry is useful, particularly in COPD patients with severe symptoms. Increased "wheezing" and low pulse oximetry values are probably useful to take into account when treatment with oral corticosteroids is considered. However, we do not know to which degree treatment with oral corticosteroids should be based on a drop in $\mathrm{FEV}_{1}$. More studies are needed to help identify the clinical findings that can be helpful in the difficult decision to prescribe this potent medication.

\section{Acknowledgments}

We thank participating patients and doctors at the following GP offices: Nordbyen legesenter, Tromsø, Allmed legesenter, Hammerfest, Alta helsesenter, Skedsmokorset legesenter, Lillestrøm legesenter, Langbølgen legesenter, Oslo, and Gransdalen legesenter, Oslo. The work was funded by the Norwegian Research Council, project 202650.

\section{Author contributions}

HM designed the study and conducted the collection of data. All authors contributed toward data analysis, drafting, and revising the paper and agree to be accountable for all aspects of the work.

\section{Disclosure}

The authors report no conflicts of interest in this work.

\section{References}

1. Hurst JR, Vestbo J, Anzueto A, et al; Evaluation of COPD Longitudinally to Identify Predictive Surrogate Endpoints (ECLIPSE) Investigators. Susceptibility to exacerbation in chronic obstructive pulmonary disease. N Engl J Med. 2010;363(12):1128-1138.

2. Al-ani S, Spigt M, Hofset P, Melbye H. Predictors of exacerbations of asthma and COPD during one year in primary care. Fam Pract. 2013;30(6): 621-628.

3. Miller MK, Lee JH, Miller DP, Wenzel SE. Recent asthma exacerbations: a key predictor of future exacerbations. Respir Med. 2007;101(3) 481-489.

4. Walters JA, Tan DJ, White CJ, Gibson PG, Wood-Baker R, Walters EH Systemic corticosteroids for acute exacerbations of chronic obstructive pulmonary disease. Cochrane Database Syst Rev. 2014;9:CD001288. 
5. Vestbo J, Hurd SS, Agusti AG, et al. Global strategy for the diagnosis, management, and prevention of chronic obstructive pulmonary disease: GOLD executive summary. Am J Respir Crit Care Med. 2013;187(4): 347-365.

6. Rowe BH, Edmonds ML, Spooner CH, Diner B, Camargo CA Jr. Corticosteroid therapy for acute asthma. Respir Med. 2004;98(4):275-284.

7. Bateman ED, Hurd SS, Barnes PJ, et al. Global strategy for asthma management and prevention: GINA executive summary. Eur Respir J. 2008;31(1):143-178.

8. Laue J, Reierth E, Melbye H. When should acute exacerbations of COPD be treated with systemic corticosteroids and antibiotics in primary care: a systematic review of current COPD guidelines. NPJ Prim Care Respir Med. 2015;25:15002.

9. Wedzicha JA. Oral corticosteroids for exacerbations of chronic obstructive pulmonary disease. Thorax. 2000;55(Suppl 1):S23-S27.

10. White AJ, O'Brien C, Hill SL, Stockley RA. Exacerbations of COPD diagnosed in primary care: changes in spirometry and relationship to symptoms. COPD. 2005;2(4):419-425.

11. Melbye H, Drivenes E, Dalbak LG, Leinan T, Høegh-Henrichsen S, Ostrem A. Asthma, chronic obstructive pulmonary disease, or both? Diagnostic labeling and spirometry in primary care patients aged 40 years or more. Int J Chron Obstruct Pulmon Dis. 2011;6:597-603.

12. van der Molen T, Willemse BW, Schokker S, ten Hacken NH, Postma DS, Juniper EF. Development, validity and responsiveness of the Clinical COPD Questionnaire. Health Qual Life Outcomes. 2003;1:13.

13. Miller MR, Hankinson J, Brusasco V, et al; ATS/ERS Task Force. Standardisation of spirometry. Eur Respir J. 2005;26(2):319-338.

14. Langhammer A, Johnsen R, Gulsvik A, Holmen TL, Bjermer L. Forced spirometry reference values for Norwegian adults: the Bronchial Obstruction in Nord-Trondelag Study. Eur Respir J. 2001;18(5):770-779.

15. Aronsson D, Tufvesson E, Bjermer L. Comparison of central and peripheral airway involvement before and during methacholine, mannitol and eucapnic hyperventilation challenges in mild asthmatics. Clin Respir J. 2011;5(1):10-18.
16. Barnes PJ. Asthma-COPD overlap. Chest. 2016;149(1):7-8.

17. Broekhuizen BD, Sachs AP, Verheij TJ, et al. Accuracy of symptoms, signs, and C-reactive protein for early chronic obstructive pulmonary disease. Br J Gen Pract. 2012;62(602):e632-e638.

18. Jones PW, Harding G, Berry P, Wiklund I, Chen WH, Kline Leidy N. Development and first validation of the COPD assessment test. Eur Respir J. 2009;34(3):648-654.

19. Leidy NK, Murray LT, Jones P, Sethi S. Performance of the EXAcerbations of chronic pulmonary disease tool patient-reported outcome measure in three clinical trials of chronic obstructive pulmonary disease. Ann Am Thorac Soc. 2014;11(3):316-325.

20. Schermer T, Leenders J, in 't Veen H, et al. Pulse oximetry in family practice: indications and clinical observations in patients with COPD. Fam Pract. 2009;26(6):524-531.

21. Hurst JR, Donaldson GC, Quint JK, Goldring JJ, Patel AR, Wedzicha JA. Domiciliary pulse-oximetry at exacerbation of chronic obstructive pulmonary disease: prospective pilot study. BMC Pulm Med. 2010;10:52.

22. Dalbak LG, Straand J, Melbye H. Should pulse oximetry be included in GPs' assessment of patients with obstructive lung disease? Scand J Prim Health Care. 2015;33(4):305-310.

23. Pluddemann A, Thompson M, Heneghan C, Price C. Pulse oximetry in primary care: primary care diagnostic technology update. Br J Gen Pract. 2011;61(586):358-359.

24. Salwan AA, Spigt M, Laue J, Melbye H. Predictors of treatment with antibiotics and systemic corticosteroids for acute exacerbations of asthma and chronic obstructive pulmonary disease in primary care. BMC Fam Pract. 2015;16:40.
International Journal of COPD

\section{Publish your work in this journal}

The International Journal of COPD is an international, peer-reviewed journal of therapeutics and pharmacology focusing on concise rapid reporting of clinical studies and reviews in COPD. Special focus is given to the pathophysiological processes underlying the disease, intervention programs, patient focused education, and self management protocols.

\section{Dovepress}

This journal is indexed on PubMed Central, MedLine and CAS. The manuscript management system is completely online and includes a very quick and fair peer-review system, which is all easy to use. Visit http://www.dovepress.com/testimonials.php to read real quotes from published authors. 